\title{
Protection from Reoxygenation Injury by Inhibition of rac1
}

\author{
Kyung-Soo Kim, ${ }^{\star \Uparrow}$ Kazuyo Takeda, ${ }^{\ddagger}$ Rachna Sethi, ${ }^{*}$ John B. Pracyk, ${ }^{*}$ Koichi Tanaka, ${ }^{*}$ Yi Fu Zhou, ${ }^{*} \mathrm{Zu}-\mathrm{Xi}$ Yu, ${ }^{\star}$ \\ Victor J. Ferrans, ${ }^{\ddagger}$ Joseph T. Bruder, ${ }^{\S}$ Imre Kovesdi, ${ }^{\S}$ Kaikobad Irani,, Pascal Goldschmidt-Clermont, ${ }^{\star \star}$ and Toren Finkel ${ }^{\star}$ \\ *Cardiology Branch, ${ }^{*}$ Pathology Section, National Heart, Lung and Blood Institute, National Institutes of Health, Bethesda, Maryland \\ 20892; ${ }^{\circledR G e n V e c ~ I n c o r p o r a t e d, ~ R o c k v i l l e, ~ M a r y l a n d ~ 20852 ; ~ " C a r d i o l o g y ~ D i v i s i o n, ~ J o h n s ~ H o p k i n s ~ S c h o o l ~ o f ~ M e d i c i n e, ~ B a l t i m o r e, ~}$ \\ Maryland 21205; **Heart and Lung Institute, Ohio State University, Columbus, Ohio 43210; and "Hanyang University, Cardiology \\ Division, Seoul, Korea 133-791
}

\begin{abstract}
We demonstrate that adenoviral-mediated gene transfer of a dominant negative rac1 gene product (N17rac1) inhibits the intracellular burst of reactive oxygen species (ROS) that occurs after reoxygenation of vascular smooth muscle cells. In contrast, expression of a dominant negative ras gene (N17ras) had no effect. Challenge of control cells and cells expressing N17rac1 with a direct oxidant stress produced an equivalent increase in intracellular ROS levels and subsequent cell death. This suggests that N17rac1 expression appears to block production of harmful oxygen radicals and does not act directly or indirectly to scavenge ROS generated during reoxygenation. Expression of N17rac1 results in protection from hypoxia/reoxygenation-induced cell death in a variety of cell types including vascular smooth muscle cells, fibroblasts, endothelial cells, and ventricular myocytes. These results suggest that reoxygenation injury requires the activation of rac proteins, and that inhibition of rac-dependent pathways may be a useful strategy for the prevention of reperfusion injury in ischemic tissues. (J. Clin. Invest. 1998. 101:1821-1826.) Key words: reoxygenation • signal transduction $\bullet$ rac $\bullet$ ras $\bullet$ adenovirus
\end{abstract}

\section{Introduction}

Although ischemia alone can produce tissue injury, previous studies have suggested that upon reperfusion, exposure of ischemic tissues to molecular oxygen greatly augments organ damage $(1,2)$. A variety of evidence suggests that a burst of reactive oxygen species (ROS) $)^{1}$ generation coincides with reoxygenation. The increase in ROS levels has been detected by several methods, including the use of electron spin resonance (3-5), as well as by note of an increase in oxidant-induced processes such as lipid peroxidation $(6,7)$. The evidence, implicating ROS as essential mediators of ischemia/reperfusion injury,

Address correspondence to Toren Finkel, Cardiology Branch, NIH, 10 Center Drive, MSC 1650, Building 10, Room 7B-15, Bethesda, MD 20892-1650.

Received for publication 25 September 1997 and accepted in revised form 23 February 1998.

1. Abbreviations used in this paper: DCF, dichlorofluorescin; DPI, diphenylene iodonium; JNK, c-jun amino terminal kinase; moi, multiplicity of infection; NAC, $\mathrm{N}$-acetyl cysteine; ROS, reactive oxygen species; VSMC, vascular smooth muscle cells.

The Journal of Clinical Investigation

Volume 101, Number 9, May 1998, 1821-1826

http://www.jci.org has centered on the observation that various chemical and enzymatic antioxidants appear to protect against the tissue damage seen with reperfusion $(1,2)$.

These previous studies have identified a pathological role for ROS generated at the time of reoxygenation. Attempts to limit postischemic tissue damage from ROS have centered predominantly on the use of antioxidants. Surprisingly, relatively little is known regarding the pathways by which ROS are generated under conditions of ischemia/reperfusion.

In phagocytic cells, where the generation of ROS plays a role in host defense, it has been appreciated for some time that the production of superoxide anions is regulated by the small GTP-binding protein rac2 $(8,9)$. More recently, studies of nonphagocytic cells have demonstrated that various growth factors and inflammatory cytokines also generate ROS upon ligand binding (10-19). The production of ROS in these cells also appears to require the participation of small GTP-binding proteins such as ras and rac1 (16-19).

In the present study, we have explored the signal transduction pathway activated by hypoxia/reoxygenation. We demonstrate a requirement for rac1, but not ras proteins, in the generation of ROS after reoxygenation. In addition, we demonstrate that inhibition of rac-dependent pathways results in protection from reoxygenation-induced cell death.

\section{Methods}

Cells. Culture of rat primary vascular smooth muscle cells (passages 5-12) was obtained as explants from the thoracic aorta. Cells were maintained in medium 199 supplemented with $10 \%$ fetal calf serum. Human umbilical vein endothelial cells were obtained from Clonetics (San Diego, CA), human embryonic lung fibroblast (MRC-5) from ATCC (Rockville, MD), and rat neonatal ventricular myocytes prepared by collagenase digestion from 2-d-old pups (Worthington Biochemical Corp., Freehold, NJ).

Hypoxia/Reoxygenation. Cells were incubated in a minimal amount of medium, and then placed in a hypoxia chamber (BillupsRothenberg, Inc., Del Mar, CA). The chamber was subsequently flushed for $30 \mathrm{~min}$ with a $95 \% \mathrm{~N}_{2} / 5 \% \mathrm{CO}_{2}$ gas mix, after which the cells were returned to a $37^{\circ} \mathrm{C}$ incubator for $16 \mathrm{~h}$. An oxygen probe demonstrated that the chamber $\mathrm{O}_{2}$ tension was $<10.0$ torr. At the end of the hypoxic period, the chamber was removed from the incubator and opened to room air and the hypoxic media rapidly replaced with oxygen-saturated medium. Levels of intracellular ROS were determined by incubating cells for $5 \mathrm{~min}$ with $10 \mu \mathrm{g} / \mathrm{ml}$ of dichlorofluorescin (DCF)-diacetate (Molecular Probes Inc., Eugene, OR), as previously described (15). Levels of DCF fluorescence represent the values from at least 60 random cells $(m e a n \pm S D)$, based on an arbitrary scale (0-255) of fluorescence intensity (15).

Cell viability was assessed 5 and $24 \mathrm{~h}$ after reoxygenation. Viability was determined by two methods, trypan blue exclusion as well as by the live/dead viability/cytotoxicity assay (Molecular Probes Inc.). For the latter method, cells were incubated for $30 \mathrm{~min}$ with calcein AM $(6 \mu \mathrm{M})$ and ethidium homodimer $(3 \mu \mathrm{M})$, and the percentage of viable cells subsequently determined by fluorescent microscopy. Un- 
der both normoxic and reoxygenation conditions, the absolute percentage of nonviable cells was significantly lower when the trypan blue method was used to determine cell viability. However, both approaches gave qualitatively similar results, with each method consistently giving a three- to fivefold increase in cell death after reoxygenation. Under the conditions of reoxygenation used, we did not directly measure whether cell death was from apoptosis necrosis, or a combination of the two processes. Except when stated otherwise, results of cell viability are from triplicate cultures (mean \pm SD) and represent one of at least three similar experiments. Statistical significance in cell viability was determined by first performing an ANOVA between the experimental groups $(P<0.05)$, and then a two-tailed unpaired $t$ test comparing N17rac1 versus the other experimental groups.

Adenoviruses. Construction of Ad.N17rac1 and Ad.N17ras was by homologous recombinant in 293 cells $(16,20,21)$. To assess the effects of adenoviral infection alone, a control adenovirus, Ad.d1312, which is deleted in the E1 region but lacks a recombinant transgene was used (22). Viruses were amplified, purified, and titered as previously described (23). Infection was with a multiplicity of infection (moi) of 100, except in cardiac myocytes where 200 moi was used. Cells were infected for $24 \mathrm{~h}$ before being made hypoxic. All cells, except the nondividing cardiac myocytes, were infected in a confluent growth-arrested state to avoid potential effects of rac1 on growth and cell cycle progression $(24,25)$. Under these conditions, we noted no obvious effect on cellular morphology (data not shown).

Gene transfer efficiencies were assessed after infection with Ad.ßGAL, an adenovirus, which encodes the Escherichia coli LacZ gene product (23). Histochemical X-gal staining of Ad.ßGAL-infected cells was as previously described (23). Western blot analysis of ras or rac expression used antibodies directed at either ras (F235; Santa Cruz Biotech., Santa Cruz, CA) or the myc-epitope tag (9E10; Santa Cruz Biotech.), which identified the N17rac1 gene product (16). $20 \mu \mathrm{g}$ of protein was loaded in each lane and bound immunoglobin was detected by enhanced chemiluminescence (Tropix, Bedford, MA). Confirmation of equal protein loading was assessed using an antibody directed at $\alpha$-tubulin (Ab-1; Calbiochem-Novabiochem Corp., La Jolla, CA).

\section{Results}

As an in vitro model for ischemia/reperfusion injury, we have used primary cultures of rat vascular smooth muscle cells (VSMC) treated for $16 \mathrm{~h}$ under hypoxic conditions, followed by reoxygenation. As demonstrated in Fig. $1 \mathrm{~A}$, compared to cells under normoxic conditions, the levels of intracellular ROS increased $\sim 10$-fold immediately after reoxygenation. Time course experiments, using the peroxide-sensitive fluorophore 2-7' DCF, demonstrated that levels of ROS were highest in the first few minutes after reoxygenation and return to baseline within $1 \mathrm{~h}$ (data not shown). We next sought to assess the protective effects of treating with the cell permeant chemical antioxidant $N$-acetyl cysteine (NAC) or the peroxide-scavenging enzyme catalase. It had been demonstrated previously that in VSMC, intracellular levels of the peroxide-scavenging enzyme catalase can be altered by extracellular catalase administration (15). Consistent with previous studies, which demonstrated a protective role for $\operatorname{ROS}$ scavengers $(1,2)$, treatment with NAC or catalase inhibited the increase in ROS after reoxygenation (Fig. $1 A$ ), as well as the subsequent increase in cell death as assessed by trypan blue exclusion (Fig. $1 \mathrm{~B}$ ). Similar results were obtained with the fluorescent live/ dead assay (fold increase $5 \mathrm{~h}$ after reoxygenation; untreated: $3.7 \pm 0.3,10 \mathrm{mM}$ NAC: $1.3 \pm 0.2,50 \mathrm{U} / \mathrm{ml}$ catalase: $1.4 \pm 0.2)$. In particular, the protective effect of catalase suggests that $\mathrm{H}_{2} \mathrm{O}_{2}$
A
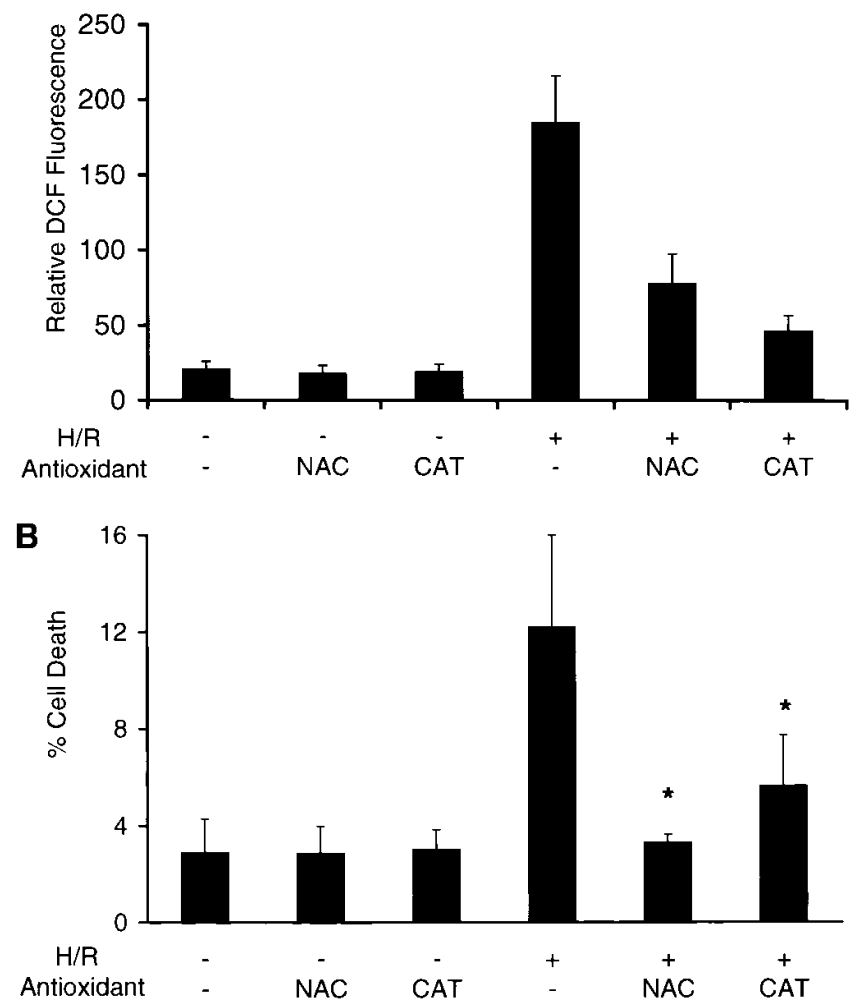

Figure 1. Levels of ROS in VSMC after hypoxia/reoxygenation. $(A)$ Intensity of 2-7' DCF fluorescence under normoxic condition $(H / R-)$ or after a 16 -h hypoxic period followed by 5 min of reoxygenation $(H / R+)$. Where indicated, cells were incubated with NAC $(10$ $\mathrm{mM})$ or $50 \mathrm{U} / \mathrm{ml}$ of catalase $(C A T)$ throughout the hypoxic period. $(B)$ Cell death, as measured by percentage of trypan blue positive cells, $5 \mathrm{~h}$ after reoxygenation $(H / R+)$ or in normoxic cells $(H / R-)$. $* P<0.05$

or radicals derived from $\mathrm{H}_{2} \mathrm{O}_{2}$ represent the major, but perhaps not the sole species, of oxygen-derived metabolites responsible for inducing cell death.

In an effort to explore the intracellular pathways required for ROS generation after reoxygenation, we constructed recombinant adenovirus encoding a dominant negative rac1 (Ad.N17rac1) or ras (Ad.N17ras) gene product. Previous studies have implicated ras-regulated pathways in hypoxic signal transduction (26-28) and rac1 in ligand-stimulated ROS generation in phagocytic and nonphagocytic cells $(8,9,16-18)$. Consistent with previous results in $\operatorname{VSMC}(29,30)$, adenoviral infection led to successful gene transfer in $>90 \%$ of infected cells (Fig. 2 A). Similarly, Western blot analysis of Ad.N17rasinfected cells demonstrated that the dominant negative ras gene product was expressed at high levels and with a significant stochimetric increase over the wild-type ras gene product (Fig. 2 C). Similarly, expression of the epitope-tagged form of rac1 was readily detected in VSMC lysate (Fig. $2 D$ ).

Given the high efficiency of adenoviral-mediated gene transfer, we next assessed the role of the ras and rac1 GTPase in reoxygenation. Examination of intracellular ROS levels revealed that in uninfected cells, reoxygenation produced a significant increase in DCF fluorescence (Fig. 3, $a$ and $e$ ). Equivalent increases in this fluorescence were seen in VSMC infected 
A

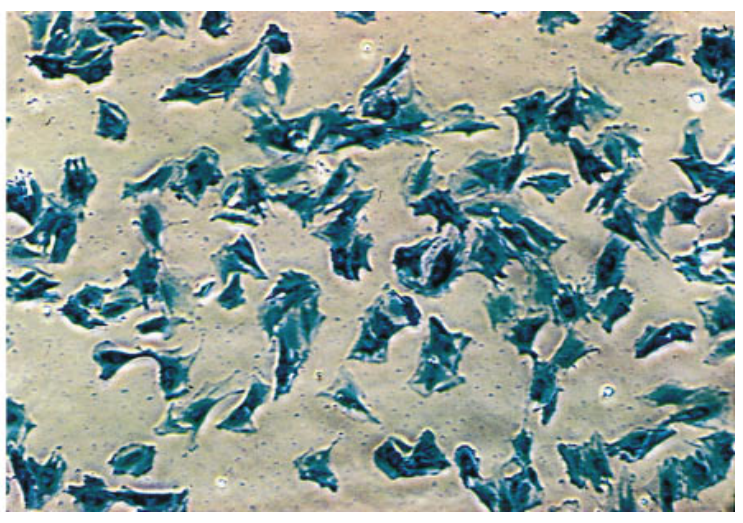

B

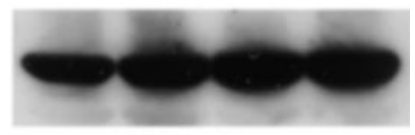

C

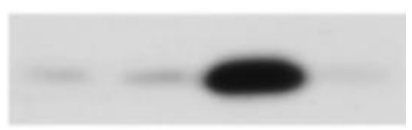

D

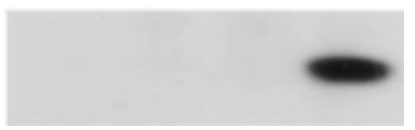

Figure 2. Assessment of adenoviral-mediated gene transfer. (A) Histochemical staining $24 \mathrm{~h}$ after infection with an adenovirus encoding $\beta$-galactosidase demonstrating near uniform gene transfer efficiency. $(B-D)$ Western blot analysis of protein lysates $(20 \mu \mathrm{g})$ obtained from (left to right) uninfected VSMC (lane 1) or VSMC infected with Ad.d1312 (lane 2), Ad.N17ras (lane 3), or Ad.N17rac1 (lane 4). Filters were subsequently probed with $(B) \alpha$-tubulin to confirm equal loading, $(C)$ an anti-ras antibody, or $(D)$ an antibody recognizing the myc epitope tag of the N17rac1 construct. with either an E1 deleted adenovirus, which lacked a recombinant transgene (Ad.d1312; Fig. $3 b$ and $f$ ), or with Ad.N17ras (Fig. 3, $c$ and $g$ ). In contrast, infection with Ad.N17rac1 produced a marked attenuation in the level of ROS, as assessed by DCF fluorescence, after reoxygenation (Fig. 3, $d$ and $h$ ).

We next assessed the effects of N17rac1 expression on cell viability. Under normoxic conditions $\left(20 \% \mathrm{O}_{2}\right)$, expression of N17racl did not affect cell viability (Fig. 4). Similarly, in cells subjected to $16 \mathrm{~h}$ of hypoxia only, the percentage of nonviable cells as assessed by the fluorescent live/dead assay or by trypan blue exclusion was not substantially increased over normoxic conditions, and expression of N17rac1 had no protective effect (data not shown). In contrast, when compared to control cells, cells expressing N17racl showed a substantially reduced level of cell death when subjected to hypoxia/reoxygenation and, subsequently, measured by the fluorescent live/dead assay. This was true at both 5 and $24 \mathrm{~h}$ after reoxygenation. Similar results were obtained using trypan blue exclusion as a marker of cell viability. (Fold increase of trypan blue positive cells $5 \mathrm{~h}$ after reoxygenation compared with normoxic control; uninfected: $3.2 \pm 0.8$, Ad.d1312: 3.0 \pm 0.2 , Ad.N17ras: $3.2 \pm 0.2$ and
Ad.N17rac: $1.1 \pm 0.3^{*}, * P<0.02$.) Somewhat surprisingly, we did observe an appreciable increase in cell death after reoxygenation when the constitutively active form of rac1 (V12rac1) was expressed (data not shown).

In phagocytic cells, rac proteins control the level of ROS by regulating the NADPH-oxidase complex $(8,9)$. Recent evidence suggests that small GTPase may play a similar role in nonphagocytic cells (16-19). In particular, the ability of ras or rac1 to regulate the intracellular redox state in fibroblasts is blocked by treatment with the flavoprotein inhibitor diphenylene iodonium (DPI), which is a known pharmacological inhibitor of the neutrophil NADPH-oxidase $(17,18)$. We, therefore, sought to test if the increase in ROS after reoxygenation, which is rac1 sensitive, was also sensitive to DPI treatment. As seen in Fig. 5, pretreatment of cells with DPI significantly inhibited the burst of ROS after reoxygenation.

Because the level of DCF fluorescence represents the balance of synthesis and degradation of ROS, we sought to ascertain whether N17rac1 expression inhibits production, or like NAC and catalase, serves to scavenge ROS. Uninfected VSMC, or VSMC infected with Ad.d1312, Ad.N17ras, or
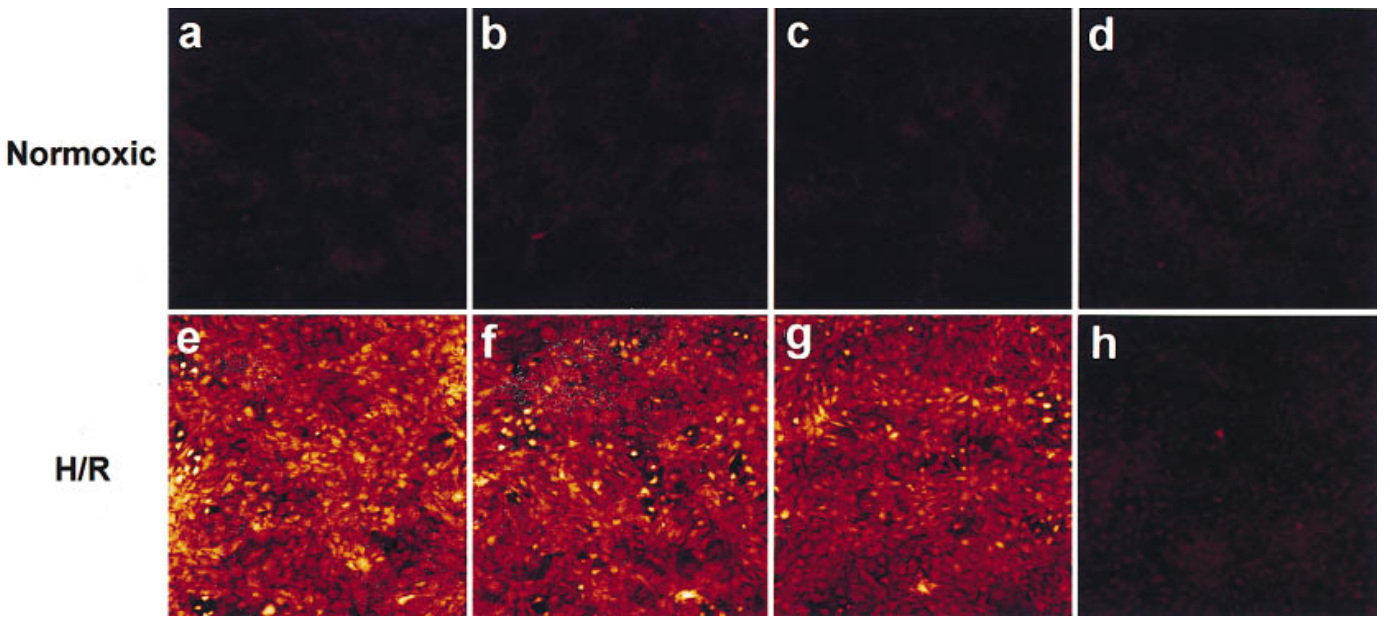

Figure 3. Effects of N17rac1 expression on the levels of ROS after hypoxia/reoxygenation. Levels of DCF fluorescence imaged by a laser confocal microscope for cells under normoxic conditions (top) or 5 min after reoxygenation (bottom) in VSMC cells that were uninfected $(a$, and $e)$; Ad.d1312-infected $(b$ and $f$ ), Ad.N17rasinfected ( $c$ and $g$ ), or infected with Ad.N17rac ( $d$ and $h$ ). 


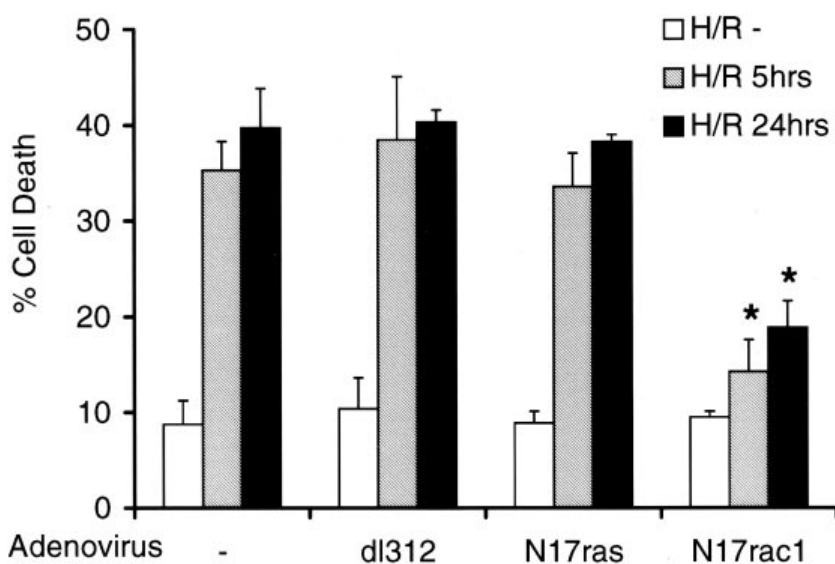

Figure 4. N17rac1 expression inhibits cell death. Percentage of nonviable VSMC under normoxic conditions $(H / R-)$ or after $16 \mathrm{~h}$ of hypoxia followed by 5 or 24 hours of reoxygenation $(H / R+)$. Viability was determined by a fluorescent live/dead assay as described. Cells were infected with $100 \mathrm{moi}$ of the indicated adenovirus for $24 \mathrm{~h}$ before being made hypoxic. Results are from one of two similar experiments, each performed in triplicate.

Ad.N17rac1, were subjected to a direct oxidative stress. Levels of intracellular DCF fluorescence after a brief $\mathrm{H}_{2} \mathrm{O}_{2}$ exposure (1 $\mathrm{mM}$ for $5 \mathrm{~min}$ ) were similar in uninfected and all adenovirus-infected cells (Fig. $6 \mathrm{~A}$ ). Similarly, Ad.N17rac1 infection did not prevent cell death after a challenge with $\mathrm{H}_{2} \mathrm{O}_{2}$ (Fig. 6 $B)$. Treatment of cells with lower doses of $\mathrm{H}_{2} \mathrm{O}_{2}(10-100 \mu \mathrm{M})$ did not result in significant cell death and produced a corresponding lower, but equal, level of DCF fluorescence in all infected cells (data not shown). This suggests that N17rac1 does not act directly or indirectly to scavenge ROS and most likely interferes with the production of damaging oxygen radicals.

Finally, we sought to determine whether the ability of N17rac1 expression to protect cells from hypoxia/reoxygenation injury was demonstrable in other cell types. Primary cultures of endothelial cells and ventricular myocytes, as well as
A
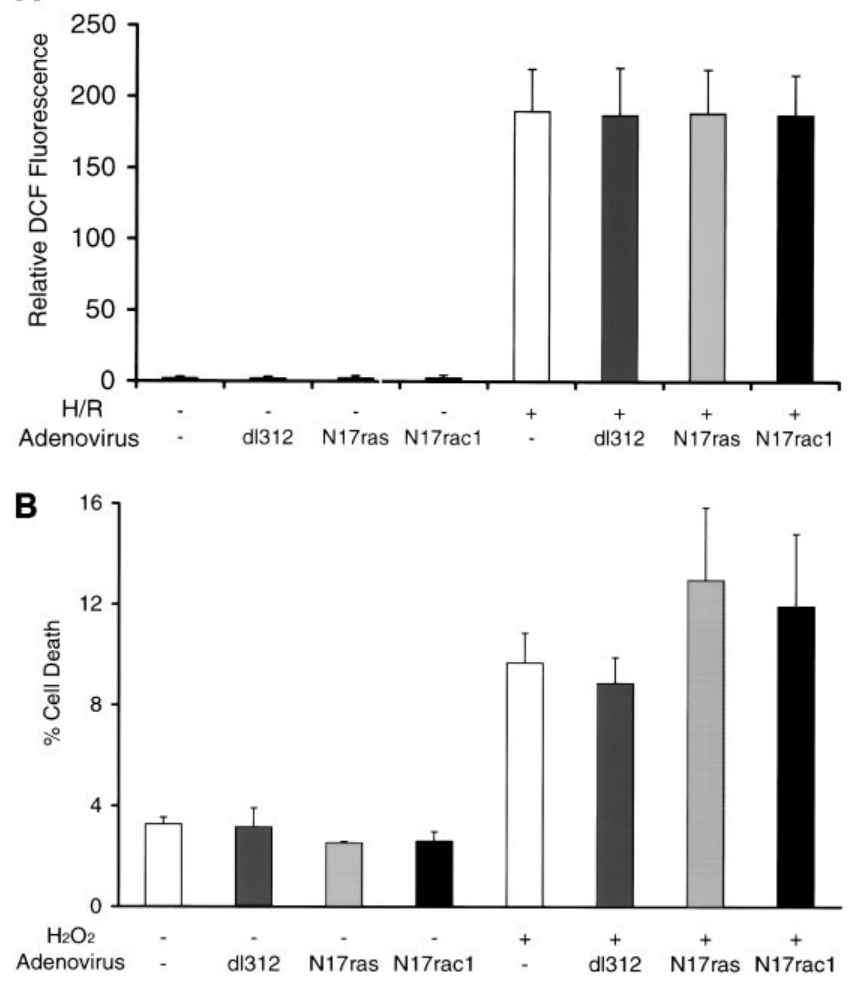

Figure 6. Rac1 proteins do not scavenge ROS. $(A)$ Levels of DCF fluorescence after a brief $\mathrm{H}_{2} \mathrm{O}_{2}(1 \mathrm{mM})$ challenge. $(B)$ Levels of cell death as assessed by trypan blue exclusion $5 \mathrm{~h}$ after a 5 -min exposure to $\mathrm{H}_{2} \mathrm{O}_{2}(1 \mathrm{mM})$. Results are from one of three similar experiments. An ANOVA between groups was not significant.

an embryonic fibroblast cell line, were subjected to a similar protocol of $16 \mathrm{~h}$ of hypoxia followed by reoxygenation. Similar to what we observed in VSMC, expression of N17rac1 in these cell types led to protection against reoxygenation-induced cell death, as assessed by trypan blue exclusion (Fig. 7).
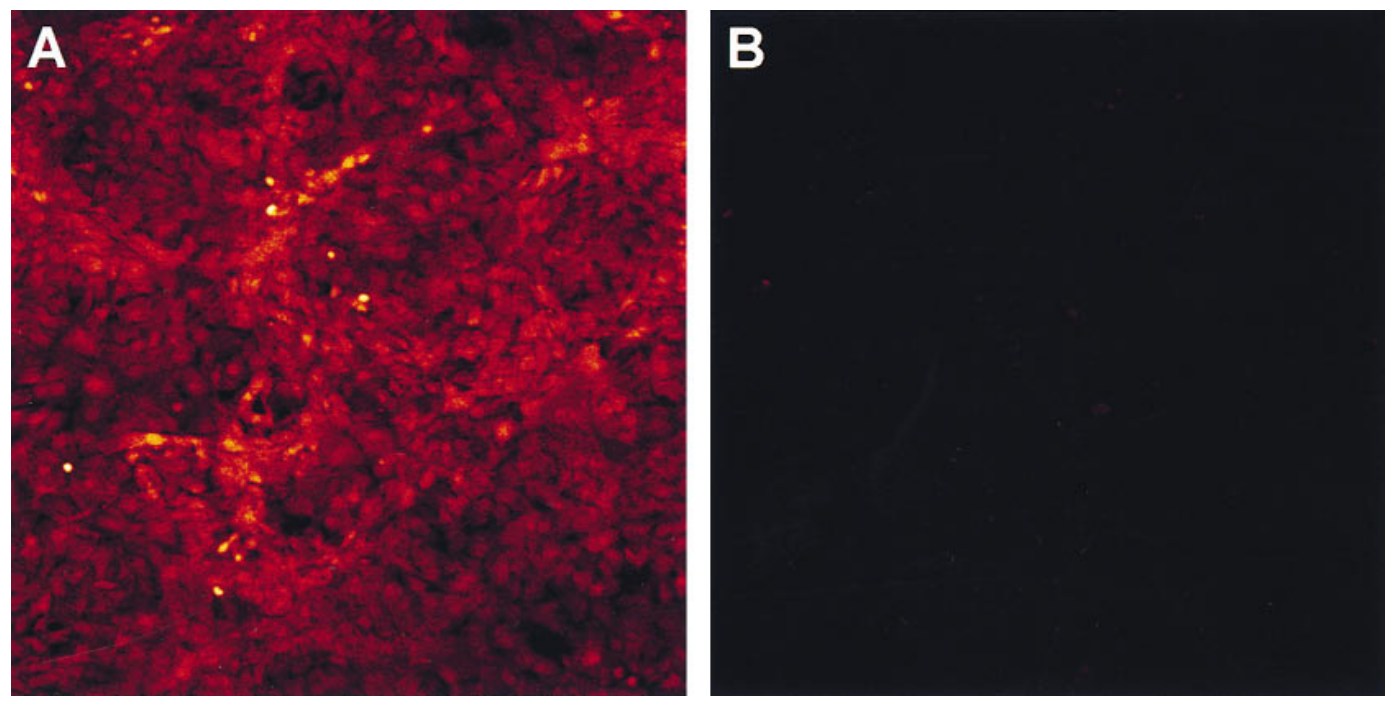

Figure 5. Effect of DPI treatment on ROS levels. VSMC were treated with $1 \mu$ M DPI throughout the 16-h hypoxic period. Levels of ROS were determined by DCF fluorescence 5 min after reoxygenation in $(A)$ untreated or $(B)$ DPItreated cells. 


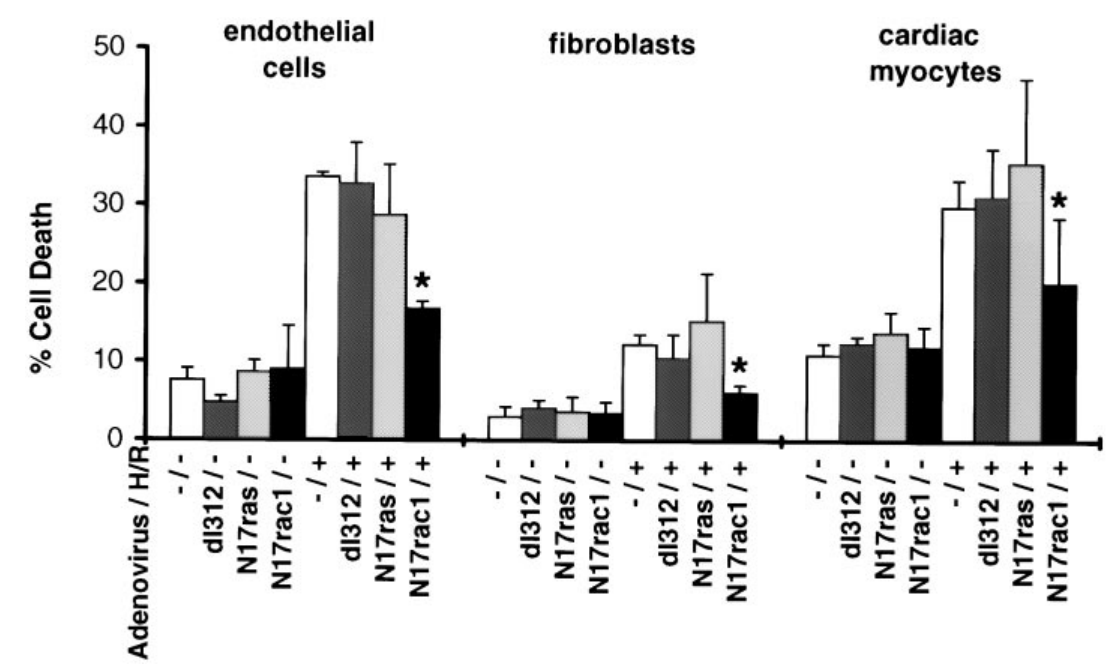

Figure 7. N17rac1 expression protects a variety of cell types. The percentage of trypan blue positive cells, determined for cultures of endothelial cells, fibroblasts, and ventricular myocytes under normoxic conditions $(H / R-)$ or subjected to hypoxia and reoxygenation $(H / R+)$. Results are from one of three similar experiments performed in triplicate. $* P<0.05$.

\section{Discussion}

We have used adenoviral-mediated gene transfer to transiently express dominant negative isoforms of rac1 and ras proteins. Previous studies have demonstrated that ras proteins are activated under hypoxic condition and regulate some aspects of hypoxic signal transduction (24-26). Similarly, ras and rac1 appear to be involved in the generation of ligand-stimulated ROS in certain cell types (16-19). Our results demonstrate a requirement for rac proteins in an intracellular pathway leading to ROS generation after hypoxia/reoxygenation. Inhibition of this pathway leads to a decrease in reoxygenation-induced cell death.

The rac-regulated enzymes, which produce ROS, and the exact species of ROS produced are uncharacterized at present. Although DCF is commonly used as a marker for intracellular $\mathrm{H}_{2} \mathrm{O}_{2}$, past studies suggest that other radicals including hydroperoxides and NO intermediates may also be detected $(31,32)$. Nonetheless, in our system, the ability of catalase (Fig. $1 A$ ) to abolish the fluorescent signal implies an important role for $\mathrm{H}_{2} \mathrm{O}_{2}$. In addition, previous results using an independent method, electron spin resonance, have suggested that expression of activated ras or rac1 isoforms leads to an increase in superoxide generation, which is subsequently dismutated to $\mathrm{H}_{2} \mathrm{O}_{2}$ (18).

The direct targets of ROS leading to cell death are also unknown. Earlier studies have suggested that the ROS generated during reoxygenation can directly induce cell death by nicking DNA or damaging cell membranes through lipid peroxidation $(1,2)$. In addition, ROS have been linked to the activation of the rac-regulated, c-jun amino-terminal kinase (JNK; 33). The activation of JNK has been observed in several in vitro and in vivo models of ischemia reperfusion (34-38). Because JNK activation has been linked to apoptosis (38-41), this represents another possible rac-regulated, ROS-modulated pathway leading to cell death. It should be noted however, that in our in vitro system of hypoxia/reoxygenation, we have observed only a modest induction of JNK or p38 kinase after reoxygenation (data not shown).

Nonetheless, our results demonstrate that regardless of the ultimate effector pathway, N17rac1 expression protects a wide variety of cell types. Included among the cells tested are endothelial cells, which are believed to be an important source of ROS (42), and cardiac myocytes, which are an important target of reperfusion injury. A strategy to prevent reperfusion injury, based on inhibiting rac or rac-dependent pathways, may be inherently more effective than an antioxidant-based approach, because such a strategy would limit generation of harmful radicals and not merely attempt to scavenge ROS after production. Although our results suggest that rac proteins regulate intracellular $\mathrm{H}_{2} \mathrm{O}_{2}$ levels, it is important to note that other toxic oxygen molecules may participate in reoxygenation injury. This may explain why we did not observe complete protection with catalase treatment or after N17rac1 expression. Nonetheless, our data suggest that efforts aimed at inhibiting rac protein function may be useful in a variety of clinical settings in which there is concern about the potential harmful effects of reperfusion injury.

\section{Acknowledgments}

We thank A. Hall (University College, London, UK) for the N17rac1 cDNA and Kathleen Zalos (National Institutes of Health, Bethesda, MD) for expert preparation of this manuscript.

\section{References}

1. Granger, N., and R.J. Korthuis. 1995. Physiologic mechanisms of postischemic tissue injury. Annu. Rev. Physiol. 57:311-332.

2. Downey, J.M. 1990. Free radicals and their involvement during long-term myocardial ischemia and reperfusion. Annu. Rev. Physiol. 52:487-504.

3. Bolli, R., M.O. Jeroudi, B.S. Patel, C.M. DuBose, E.K. Lai, R. Roberts, and P.B. McCay. 1989. Direct evidence that oxygen-derived free radicals contribute to post ischemic myocardial dysfunction in the intact dog. Proc. Natl. Acad. Sci. USA. 86:4695-4699.

4. Bolli, R., B.S. Patel, M.O. Jeroudi, E.K. Lai, and P.B. McKay. 1988. Demonstration of free radical generation in "stunned" myocardium of intact dogs with the use of the spin trap $\alpha$-phenyl- $N$-tert-butyl nitrone. J. Clin. Invest. $82: 476-485$.

5. Zweier, J.L., J.T. Flaherty, and M.L. Weisfedlt. 1987. Direct measurement of free radical generation following reperfusion of ischemic myocardium. Proc. Natl. Acad. Sci. USA. 84:1404-1407.

6. Lindsay, T., P. Walker, D. Mickle, and A. Romaschin. 1988. Measurement of hydroxy conjugated dienes after ischemia/reperfusion in canine skeletal muscle. Am. J. Physiol. 254:H578-H583.

7. Rubin, B.B., G. Chang, S. Liauw, A.M. Young, A. Romaschin, and P.M. Walker. 1992. Phospholipid peroxidation deacylation and remodeling in post- 
ischemic skeletal muscle. Am. J. Physiol. 263:H1695-H1702.

8. Abo, A., A. Pick, A. Hall, N. Tony, C. Teahan, and A. Segal. 1991. Activation of the NADPH oxidase involves the small GTP-binding protein Rac2. Nature. 353:668-670.

9. Knaus, U., P. Heyworth, T. Evans, J. Curnutte, and G. Bokoch. 1991. Regulation of phagocyte oxygen radical production by the GTP-binding protein Rac2. Science. 254:1512-1515.

10. Meier, B., H.H. Radeke, S. Selle, M. Younes, H. Sies, K. Resche, and G. Habermehl. 1989. Human fibroblasts release reactive oxygen species in response to interleukin-1 or tumour necrosis factor- $\alpha$. Biochem. J. 263:539-545.

11. Griendling, K.K., C.A. Minieri, J.D. Ollerenshaw, and R.W. Alexander. 1994. Angiotensin II stimulates NADH and NADPH oxidase activity in cultured vascular smooth muscle cells. Circ. Res. 74:1141-1148.

12. Ohba, M., M. Shibauma, T. Kuroki, and K. Nose. 1994. Production of hydrogen peroxide by transforming growth factor- $\beta 1$ and its involvement induction of egr-1 in mouse osteoblastic cells. J. Cell Biol. 126:1079-1088.

13. Lo, Y.Y., and T.F. Cruz. 1995. Involvement of reactive oxygen species in cytokine and growth factor induction of $c$-fos expression in chondrocytes. $J$. Biol. Chem. 270:11727-11730.

14. Shibanuma, M., T. Kuroki, and K. Nose. 1990. Stimulation by hydrogen peroxide of DNA synthesis, competence family gene expression and phosphorylation of a specific protein in quiescent Balb/3T3 cells. Oncogene. 5:1025-1032.

15. Sundaresan, M., Z. Yu, V. Ferrans, K. Irani, and T. Finkel. 1995. Requirement for generation of $\mathrm{H}_{2} \mathrm{O}_{2}$ for platelet-derived growth factor signal transduction. Science. 270:296-299.

16. Sulciner, D., K. Irani, Z.Y. Yu, V.J. Ferrans, P.J. Goldschmidt-Clermont, and T. Finkel. 1996. Rac1 regulates a cytokine-stimulated, redox-dependent pathway necessary for NF-кB activation. Mol. Cell. Biol. 16:7115-7121.

17. Sundaresan, M., Z.Y. Yu, V.J. Ferrans, J.S. Gutkin, K. Irani, P.J. Goldschmidt-Clermont, and T. Finkel. 1996. Regulation of reactive-oxygen species generation in fibroblasts by Rac1. Biochem. J. 318:379-382.

18. Irani, K., Y. Xiu, J.L. Zweir, S. Sollot, L. Rosolowski, E.R. Fearon, M. Sundarasan, T. Finkel, and P.J. Goldschmidt-Clermont. 1997. Mitogenic signaling mediated by oxidants in ras-transformed fibroblasts. Science. 275:16491652 .

19. Gulbins, E., B. Brenner, K. Schlottman, J. Welsch, H. Heinle, U. Koppenhoefer, O. Linderkamp, K.M. Coggeshall, and F. Lang. 1996. Fas-induced programmed cell death is mediated by a Ras-regulated $\mathrm{O}_{2}$ synthesis. Immunology. 89:205-212.

20. McGrory, W.J., D.S. Bautista, and F.L. Graham. 1988. A simple technique for the rescue of early region I mutations into infectious human adenovirus type 5. Virology. 163:614-617.

21. Chinnadurai, G., S. Chinnadurai, and J. Brusca. 1979. Physical mapping of a large-plaque mutation of adenovirus type 2. J. Virol. 32:623-628.

22. Jones, N., and T. Shenk. 1979. Isolation of adenovirus type 5 host range deletion mutants defective for transformation of rat embryo cells. Cell. 17:683-689.

23. Guzman, R.J., E.A. Hirschowitz, S.L. Brody, S.L. Crystal, S.E. Epstein, and T. Finkel. 1994. In vivo suppression of injury-induced vascular smooth muscle cell accumulation using adenovirus-mediated transfer of the herpes simplex virus thymidine kinase gene. Proc. Natl. Acad. Sci. USA. 91:10732-10736.

24. Olson, M.F., A. Ashworth, and A. Hall. 1995. An essential role for Rho, rac, and cdc42 GTPases in cell cycle progression through $\mathrm{G}_{1}$. Science. 269:12701272.

25. Moore, K.A,. R.A. Sethi, A.M. Doanes, T.M. Johnson, J.B. Pracyk, M. Kirby, K. Irani, P.J. Goldschmidt-Clermont, and T. Finkel. 1997. Rac1 is required for cell proliferation and G2/M progression. Biochem. J. 326:17-20.

26. Mukhopadhyay, D., L. Tsiokoas, X-M. Zhou, D. Foster, J.S. Brugge, and V.P. Sukhatme. 1995. Hypoxic induction of human vascular endothelial growth factor expression through c-Src activation. Nature. 375:577-581.

27. Koong, A.C., E.Y. Chen, N.F. Mivechi, N.C. Denko, M. Stambrook, and A.J. Giaccia. 1994. Hypoxic activation of nuclear factor-кB is mediated by a Ras and Raf signaling pathway and does not involve MAP kinase (ERK1 or ERK2). Cancer Res. 54:5273-5279.

28. Seko, Y., K. Tobe, N. Takahashi, Y. Kaburagi, T. Kadowaki, and Y. Yazaki. 1996. Hypoxia and hypoxia/reoxygenation active Src family tyrosine kinases and p $21^{\text {ras }}$ in cultured rat cardiac myocytes. Biochem. Biophys. Res. Commun. 226:530-535.

29. Guzman, R.J., P. Lemerchand, R.G. Crystal, S.E. Epstein, and T. Finkel. 1993. Efficient and selective adenoviral-mediated gene transfer into vascular neointima. Circulation. 88:2838-2848.

30. Lee, S.W., B.C. Trapnell, J.J. Rade, R. Virmani, and D.A. Dichek. 1993. In vivo adenoviral vector-mediated gene transfer into balloon-injured rat carotid arteries. Circ. Res. 73:797-807.

31. Cathcart, R., E. Schwiers, and B.A. Ames. 1983. Detection of picomole levels of hydroperoxides using a fluorescent dichlorofluorescein assay. Anal. Biochem. 134:111-116.

32. Rao, K.M., J. Padmanabhan, D.L. Kilby, H.J. Cohen, M.S. Currie, and J.B. Weinberg. 1992. Cytometric analysis of nitric oxide production in human neutrophils using dichlorofluorescein diacetate in the presence of a calmodulin inhibitor. J. Leukocyte Biol. 51:496-500.

33. Rao Lo, Y.Y.C., J.M.S. Wong, and T.F. Cruz. 1996. Reactive oxygen species mediate cytokine activation of c-Jun amino terminal kinases. J. Biol. Chem. 271:15703-15706.

34. Pombo, C.M., J.V. Bonventre, J. Arruch, J.R. Woodgett, J.M. Kyrinkis, and T. Force. 1994. The stress-activated protein kinases are major c-Jun aminoterminal kinases activated by ischemia and reperfusion. J. Biol. Chem. 269: 26546-26551.

35. Morooka, H., J.V. Bonventre, C.M. Pombe, and J.M. Kyriakis. 1995. Ischemia and reperfusion enhance ATF2 and cJun binding to cAMP response elements and to an AP-1 binding site from the c-jun promoter. J. Biol. Chem. 270:30084-30092.

36. Knight, R.J., and D.B Buxton. 1996. Stimulation of c-Jun kinase and mitogen-activated protein kinase by ischemia and reperfusion in the perfused rat heart. Biochem. Biophys. Res. Commun. 213:83-88.

37. Bogoyevitch, M.A., J. Gillespie-Brown, A.J. Ketterman, S.J. Fuller, R. Ven-Levy, A. Ashworth, L.J. Marshall, and P. Sugden. 1996. Stimulation of the stress-activated mitogen-activated protein kinase subfamilies in perfused heart: p38/ERK mitogen-activated protein kinases and c-Jun N-terminal kinases are activated by ischemia/reperfusion. Circ. Res. 79:162-173.

38. Laderoute, K.R., and K.A. Webster. 1997. Hypoxia/reoxygenation stimulates jun kinase activity through redox signaling in cardiac myocytes. Circ. Res. 80:336-344

39. Xia, Z., M. Dickens, J. Raingeaud, R.J. Davis, and M.E. Greenberg. 1995. Opposing effects of ERK and JNK-p38 MAP kinases on apoptosis. Science. 270:1326-1331.

40. Johnson, L.N., A.M. Gardner, K.M. Diener, C.A. Lange-Carter, J. Gleavy, M.B. Jape, A. Minden, M. Karin, L.I. Zon, and G.L. Johnson. 1996. Signal transduction pathways regulated by mitogen-activated/extracellular response kinase kinase induced cell death. J. Biol. Chem. 271:3229-3237.

41. Verhij, M., R. Bose, X.H. Lin, B. Yao, W.D. Jarvis, S. Grant, M. Birrer, E. Szaboo, L.I. Zon, J.M. Kyrinkis, et al. 1996. Requirement for ceramide-initiated SAPK/JNK signaling in stress-induced apoptosis. Nature. 380:75-79.

42. Zweier, J.L., P. Kuppusamy, S. Thompson-Gorman, D. Klunk, and G.A. Lutty. 1994. Measurement and characterization of free radical generation in reoxygenated human endothelial cells. Am. J. Physiol. 266:C700-C708. 